\title{
European Physical Society establishes Hewlett Packard Europhysics Award for Outstanding Achievement in Solid State Physics
}

A prize of Swiss francs 20000 .will be awarded each year by EPS to one or several physicists, without restriction as to nationality, thanks to an annual donation made to the Society by Hewlett-Packard S. A., the European headquarters organization of the Hewlett-Packard Company, Palo Alto, California.

According to the charter "the award shall be given in recognition of a recent work by one or more

\section{Meetings}

For a full list of events see the latest Meetings Issue of Europhysics News 5, (May 1974). Notification of the meetings announced in this issue has been received recently.

The order of information is: date, title, venue, and contact for information.

\section{Conferences 1974}

24 - 26 September

High Resolution Molecular Spectroscopy Novosibirsk, USSR

Yu. S. Makyshin, Institute of Atmospheric Optics, Tomsk 29

11 - 12 October

Session d'Automne de la Société Suisse de Physique

Neuchâtel, Switzerland

M. Guenin, Département de Physique Théorique, 32, bd d'Yvoy, $\mathrm{CH}$ - 1211 Genève 4

25 - 29 October

International Conference on High Pressure Kyoto, Japan

J. Ohsugi, Science Department, Kyoto University, Kawaramachi 53, Shogoin-Sa Kyoku, Kyoto

\section{October - 2 November}

60th Annual Congress of the Italian Physical Society

Bologna, Italy

Secretariat, Italian Physical Society, Via L. Degli Andalò 2, I - 40124 Bologna

11 - 15 November

Quantum Crystals

Tbilissi, USSR

E.L. Andronikashvili, Institute of Physics, Academy of Sciences of the Georgian SSR, Tbilissi

\section{5}

\footnotetext{
6-8 January

12th Annual Solid State Physics Conference and Specialist Symposia on Phase Transitions and Liquid Crystals

Manchester, UK

The Meetings Officer, The Institute of Physics, 47. Belgrave Square, London SWIX $80 X$
}

individuals in the area of physics of condensed matter, specifically work leading to advances in the fields of electronic, electrical and materials engineering which, in the opinion of the Society's selection committee, represents scientific excellence. $R e-$ cent work is defined to mean completed within five years prior to the award. The award may be be given for either pure or applied research at the discretion of the Society. "
The award shall be presented by the EPS at an annual ceremony to a recipient selected by a committee of scientists. The selection committee is to be appointed by the Executive Committee of the EPS.

The first award will be made on the occasion of the Third EPS General Conference in Bucharest in September 1975 .

\section{4 - 28 February}

First European Meeting of Solar Astronomers Florence, Italy

C. de Jager, Space Research Laboratory of the Astronomical Institute, Beneluxlaan 21 . Utrecht, The Netherlands

\section{4- 26 March}

Nuclear Interactions at Medium and Low Energies Harwell, UK

T.W. Coulon, AERE Harwell, Didcot, Berkshire OX11 ORA

\section{4 - 27 March}

International Conference on Automatic Image Processing in Astronomy

Utrecht, The Netherlands

C. de Jager, Space Research Laboratory of the Astronomical Institute, Beneluxlaan 21, Utrecht

9-11 April

Magnetic Resonance in Conductors and Disordered Materials

Paris, France

J. H. Strange, The Physics Laboratory, The University, Canterbury, Kent, UK

\section{3 - 27 June}

2nd Laser Spectroscopy Conference Megève, France

J.C. Pebay-Peyroula, Laboratoire de Spectrométrie Physique, B.P. No 53 F - 38041 Grenoble Cedex

1 - 5 July

Stars and Galaxies from an Observational Point of View

Tbilissi, USSR

E.K. Kharadze, Astrophysical Observatory, Abastumani, Georgia

\section{7- 11 July}

7th EGAS Conference on Atomic Spectroscopy Grenoble, France

J. C. Pebay-Peyroula, Laboratoire de Spectrométrie Physique, Boite Postale 53 , F - 38041 Grenoble Cedex

\section{5 - 30 August}

Fourth International Symposium on Polarization Phenomena in Nuclear Reactions

Zurich, Switzerland

W. Grüebler, Laboratorium für Kernphysik, Eidgenössische Technische Hochschule, Hönggerberg, $\mathrm{CH}$ - 8049 Zurich

\section{'Summer' Schools 1974}

22 September - 1 October

The Investigation of Nuclear Structure by Scattering Processes at High Energies Erice, Italy

H. Schopper, Deutsches Elektronen-Synchrotron DESY, Notkestieg 1, D - 2000 Hamburg 52

23 September - 2 October

Collision Phenomena in Vacuum

Lake Balaton, Hungary

G. Szigeti, Research Institute for Technical Physics of the Hungarian Academy of Sciences, Pf 76, $\mathrm{H}-1325$ Budapest, Ujpest 1

30 September - 27 October

Introduction to Modern Thoretical Geodesy Erice, Italy

A. Marussi, Istituto di Geodesia e Geofisica, Università di Trieste, 1 - 34100 Trieste

16 - 25 October

Hadrons and their Constituents

Erice, Italy

G. Preparata, CERN - Th Division $\mathrm{CH}-1211$ Geneva 23

29 December - 10 January

Bat Sheva Seminar - Frontiers in Solid State Physics

Haifa, Israel

Amiran Ron, Technion, Israel Institute of Technology, Haifa

Editor: Lorette Etlenne-Amberg.

Editorlal Advlsory Panel:

G.J. Béné, B. Glovanninl,

G. Harbeke, E.N. Shaw, J.J. Went.

All correspondence to: Editor, EUROPHYSICS NEWS,

European Phyaical Soclety,

P.0. Box 39,

CH - 1213 Petit-Lancy 2

Phone: Geneva 931132

Switzerland.

Published by the European Physical Socloty

Printed by: Ed. Cherix et Flianosa S.A. CH - 1260 Nyon, Switzerland. 